\title{
Descriptive study on socio-demographic profile, pattern of injuries, aetiology and outcome of domestic violence at a tertiary care centre of Batticaloa district
}

\author{
Rajathurai Nisanthan ${ }^{1}$, Peethamparam Jeepara ${ }^{1}$, Selladurai Pirasath ${ }^{2}$ \\ ${ }^{1}$ Teaching Hospital, Batticaloa, Sri Lanka. \\ ${ }^{2}$ Teaching Hospital, Jaffna, Sri Lanka.
}

Keywords: Domestic violence;females; sociodemographics; perceptions; injuries

\begin{abstract}
\section{Introduction}

Domestic violence is common serious health problem in South Asian countries including Sri Lanka which has an immense impact on people's physical, psychological and social health in a community.
\end{abstract}

\section{Objectives}

To determine the socio-demographic characteristics, the pattern of injuries and outcome among patients with domestic violence injuries at a tertiary care centre in Batticaloa, Sri Lanka.

\section{Methods}

Fifty nine female patients with domestic violence injuries were recruited in our descriptive, cross-sectional study. A predesigned interviewer based questionnaire was used to collect data from the participants and was analysed statistically by simple proportions and percentage using SPSS analytical package (version 21). The Ethical Review Committee, Faculty of Health Care Sciences, Eastern University granted the ethical approval for the study.

\section{Results}

Fifty nine female respondents were recruited. The common demographic characteristic observed were the 21 to 40 years age group was poor socio-economic and educational status. The husbands acted as the perpetrators among most victims $(42.4 \%)$. Majority of the respondents $(71.2 \%)$ reported that their husbands abuse them under the influence of alcohol. Most respondents had sustained minor injuries including contusion $(64.4 \%)$, laceration $(15.3 \%)$ and fractures $(18.6 \%)$ among them. The common reasons for violence encountered among them were arguments $(67.8 \%)$ and financial reasons (16.9\%). Even though $45.8 \%$ of respondents had been abused

Correspondence: Rajathurai Nisanthan

E-mail: rnishanthan@gmail.com

Received: 29-01-2019 Accepted: 07-06-2019

(iD) http://orcid.org/0000-0001-5639-7906

DOI: http://doi.org/10.4038/sljs.v37i2.8623 on multiple occasions, $86.4 \%$ of them have not reported previous abuse legally. Most people denied seeking medicolegal action due to fear of family separation and poor knowledge of services available for domestic violence.

\section{Conclusion}

Domestic violence commonly affects the young female and is associated with illiteracy and poor socio-economic status of the victims. Arguments and financial issues are the commonest reason for violence. Most people are not aware of the potential of seeking medico-legal action and available services to help them

\section{Introduction}

Domestic violence is the most prevalent form of violence against females globally [1] and is a grave socio-clinical concern in every community and culture in Sri Lanka leading to attention from the medical community. Kalokhe et al recently proposed a culturally tailored operational definition of domestic violence which seeks to expand on the existing WHO definition by taking in to consideration several key themes regarding behaviours and acts constituting domestic violence. It includes control over decision-making ability of women, social relationship with society members, financial issues related to food and property, sexual abuse and sexual relationship with others, physical abuse, psychological abuse and the perpetration of domestic violence [1]. Domestic violence has an immense impact on people's physical, psychological and social health in a community [2]. The prevalence of domestic violence in South-East Asia and Sri Lanka is $37.8 \%$ [2] and $25-30 \%$ [3] respectively. $45 \%$ of women are exposed to violence by their husbands in India [2]. $24-34 \%$ of women have affected domestic violence in different parts of Sri Lanka [3]. The highest prevalence was noted in the Northern and Eastern parts of Sri Lanka during the civil war for the last three decades [3].

Gathering data on domestic violence from patients is difficult as they think that disclosing information is an intimate, sensitive and confidential issue. Our study aimed to describe the socio-demographic characteristics, the pattern of injuries, and the outcome of female patients with domestic violence injuries presenting to a tertiary care centre, in Batticaloa district, Sri Lanka. 


\section{Materials and Methods \\ Study settings}

A descriptive cross-sectional study was carried in a tertiary care centre, Batticaloa district, Sri Lanka. Female patients who were victims of domestic violence were included. The Batticaloa Teaching hospital is the only tertiary care hospital in Batticaloa district. Therefore, the majority of the patients with domestic violence injuries from all over the Batticaloa district admit to the general surgical wards of Teaching Hospital, Batticaloa.

\section{Sampling procedure and sample size}

Fifty nine female patients with injuries associated with domestic violence were recruited from all surgical units, at the Teaching hospital Batticaloa by convenient sampling method. The study was conducted for a period of 6 months from January 2017 to June 2017.

\section{Ethics approval}

The ethical approval was obtained from the Ethical Review Committee, Faculty of Health Care Sciences, and Eastern University. After proper approval, a hudred patients with their informed written consent were included in the study. The subjects were interviewed to gather clinical and demographic details.

\section{Inclusion and exclusion criteria}

A cohort of 59 female patients who had physical injuries exposed to domestic violence from minor to major injuries admitted to general surgical wards, Teaching hospital, Batticaloa were further analysed in this descriptive crosssectional, qualitative phenomenological survey. The patients who were

pregnant or below 18 years of age were excluded from the study.

\section{Development of Questionnaires}

Domestic violence Fact Questionnaire was designed as a tool, using the existing literature to assess the socio-demographic, pattern of injuries, awareness and outcome of domestic violence among those patients. The questionnaire was prepared and expert validated in English and was translated into Tamil and Sinhala language. The questionnaire consists of several questions to assess the patients' socio-demographic characteristics, a pattern of injuries, reasons, awareness and outcome of domestic violence. The patients who met the inclusion criteria were interviewed to assess sociodemographic character-istics, pattern of injuries, and possible causes of domestic violence.

\section{Data analysis}

Data were collected and were entered in Microsoft Excel sheet. All data were analysed using SPSS analytical package.
The results were represented as numbers and percentages for continuous variables. A P value of $<0.05$ was considered statistically significant.

\section{Results}

Fifty nine patients with injuries associated with domestic violence were recruited from the surgical units, Teaching Hospital, Batticaloa.

\section{Demographic characteristics}

The basic demographic characteristics of patients with domestic violence are shown in Table 1. Most of the domestic violence occurred among patients with an age of 21 - 40 years (55.9\%), while low prevalence was noticed among the patients with age of $61-80$ years $(6.8 \%)$. The patients with low literacy rates or below primary education $(59.3 \%)$ were most vulnerable to domestic violence injuries in our study. Besides, high prevalence was noticed among married females $(91.5 \%)$. Housewives (74.6\%) and labourers (13.6\%) were commonly affected by domestic violence (Table1). Moreover, it was higher among the patients with low monthly income $(91.5 \%)$ compared to patients with higher monthly income $(8.5 \%)$.

\section{The characteristic pattern of injuries}

The injuries were mild to major in severity. Injuries commonly involved head, limb and multiple body areas (Table 2). Most people sustained minor injuries which were contusion (64.4\%) and laceration (15.3\%) (Table 2). The

Table 1. Sociodemographic characteristics of the respondents (Nos: 59)

\begin{tabular}{|c|c|c|c|}
\hline $\begin{array}{l}\text { Socio-demographic } \\
\text { characteristics }\end{array}$ & & Nos & $\begin{array}{c}\text { Percentage } \\
\text { (\%) }\end{array}$ \\
\hline \multirow[t]{4}{*}{ Age } & $<20$ years & 7 & 11.9 \\
\hline & $21-40$ years & 33 & 55.9 \\
\hline & $41-60$ years & 15 & 25.4 \\
\hline & $60-80$ years & 4 & 6.8 \\
\hline \multirow[t]{2}{*}{ Marital Status } & Single & 54 & 91.5 \\
\hline & Married & 5 & 8.5 \\
\hline \multirow[t]{4}{*}{ Educational Status } & No schooling & 9 & 15.2 \\
\hline & Primary level & 26 & 44.1 \\
\hline & Ordinary Level & 19 & 32.2 \\
\hline & Advanced level & 5 & 8.5 \\
\hline \multirow[t]{4}{*}{ Occupation } & Business & 3 & 5.1 \\
\hline & Labourers & 8 & 13.6 \\
\hline & Students & 4 & 6.8 \\
\hline & Housewife & 44 & 74.6 \\
\hline \multirow[t]{5}{*}{ Monthly income } & Rs. $<9,999$ & 7 & 11.9 \\
\hline & $\begin{array}{l}\text { Rs } 10,000- \\
19,999\end{array}$ & 21 & 35.6 \\
\hline & $\begin{array}{l}\text { Rs } 20,000- \\
29,999\end{array}$ & 26 & 44.1 \\
\hline & $\begin{array}{l}\text { Rs } 30,000- \\
39,999\end{array}$ & 4 & 6.8 \\
\hline & $\begin{array}{l}\text { Rs } 40,000- \\
49,999\end{array}$ & 1 & 1.7 \\
\hline
\end{tabular}


victims were injured by several weapons such as wooden stick (Nos-18), metal bar (Nos-3), stone (Nos-7), door bar (Nos-6), metal bar (Nos-3) broomstick (Nos-3), knife (Nos1), helmet (Nos-1). Husbands (42.4\%), male siblings (26.1\%), partner's family members $(16.9 \%)$, acted as the perpetrators (Table 3).

\section{Reasons for perpetration of domestic violence}

Arguments (67.8\%) and financial issues (16.9\%) were common reasons encountered among them (Table 4). Even though $45.8 \%$ of respondents had been abused several times, $86.4 \%$ of them have not reported previous abuse to the authorities. Sixty-eight percent had suffered domestic violence several times in the previous year. $48 \%$ of the victims lived with their abusers and avoided seeking medicolegal action due to fear of family separation and isolation from the community (Nos- 9), future of children (Nos- 11), financial dependence (Nos- 7), and poor knowledge of services available for domestic violence (Nos-31). Majority

Table 2. Characteristic pattern of injuries associated with domestic violence reported by the respondents (Nos: 59)

\begin{tabular}{lll}
\hline Pattern of injuries & NOs & Percentage (\%) \\
\hline Head injuries & 13 & 22 \\
Chest and abdominal injuries & 13 & 22 \\
Upper limb injuries & 18 & 30.5 \\
Lower limb injuries & 2 & 3.4 \\
Multiple injuries & 13 & 22 \\
& & \\
\hline Type of injuries & NOs & Percentage (\%) \\
\hline Contusions & 38 & 64.4 \\
Lacerations & 9 & 15.3 \\
Stab injuries & 1 & 1.7 \\
Limb Fractures & 11 & 18.6 \\
\hline
\end{tabular}

Table 3. Perpetrators of violence reported by the respondents (Nos-59)

\begin{tabular}{lll}
\hline Perpetrators & No's & Percentage (\%) \\
\hline Husband & 25 & 42.4 \\
Children & 3 & 5.1 \\
Grandchildren & 2 & 3.4 \\
Male Siblings & 16 & 27.1 \\
Female siblings & 2 & 3.4 \\
Other relatives & 1 & 1.7 \\
Partners Family members & 10 & 16.9 \\
\hline
\end{tabular}

of the respondents $(71.2 \%)$ reported that their husbands abuse them under the influence of alcohol.

\section{The outcome of domestic violence of patients}

All patients had mild to severe physical injuries and psychological consequences. Minor injuries were managed with suturing of laceration among $15.3 \%$ of cases and observation of head injuries. The major abdominal injury required exploratory laparotomy and thoracotomy among $3.4 \%$ of cases. Orthopaedic interventions were required for fractures and dislocations among $17.6 \%$ of cases. Medicolegal action was required in most cases. They were managed with a consultation with a gender-based violence team and psychiatric counselling. There were no deaths reported in our study. A statistically significant association was observed among domestic violence injuries and the socio-demographic

Table 4. Reasons of violence reported by the respondents (Nos-59)

\begin{tabular}{lll}
\hline Reasons & NOs & Percentage (\%) \\
\hline & & \\
Arguments & 40 & 67.8 \\
Love affairs & 2 & 3.4 \\
Financial issues & 10 & 16.9 \\
Competition for properties & 6 & 10.2 \\
Accidental & 2 & 3.4
\end{tabular}

characteristic pattern of respondents in our study especially age, marital status and educational status.

\section{Discussion}

Domestic violence is the form of abuse which ranges from physical, psychological or sexual acts usually against females by partners, boyfriends or family members. A higher proportion of domestic violence was observed among females $(59 \%)$ than males $(41 \%)$ in our study. The studies conducted in Turkey [4] and in rural Bangladesh [5] have revealed that the occurrence of domestic violence was $38.3 \%$ and $67 \%$ among females respectively. A study done in 2013 has shown that $22 \%$ of females have suffered from domestic violence from their sex partner. Also, it revealed that $24 \%$ of male participants perpetrated domestic violence during their lifetime [6]. A significant number of women (22\%) were exposed to recurrent domestic violence in the preceding year in a previous study done in 2001 in Sri Lanka [7]. Our study also revealed that $68 \%$ of our study population had experienced multiple instances of domestic violence in the last year.

The socio-demographic background of respondents had associations with the prevalence of domestic violence in our study. Most importantly, domestic violence was observed among patients with 20-40 years of age and poor educational status. Also, married women have suffered from frequent and severe domestic violence injuries than unmarried women. Low educational status and low family -income level showed a positive correlation with the rate of domestic violence in a study conducted in the Sivas province of Turkey [4] and our study also supported the same finding. 
The males were the perpetrators among most of the female victims (79\%). $42.4 \%$ of victims were housewives whose husbands were the perpetrators. Majority of the respondents (71.2\%) reported that their husbands abuse them under the influence of alcohol. A study carried out in Batticaloa revealed that alcoholism and drug abuse had influences among domestic violence injuries [6]. Most females have reported that slapping was the specific act of physical assault in domestic violence injuries. It was also noted among abusers of siblings.

Also, slapping (80\%) and kicking/punching/ hitting (74\%) were reported as common types of physical abuse in a study done in Gujarat [8].

Arguments (67.8\%) and economic factors (16.9\%) were common causes of domestic violence in our study whereas economic problems (31.4\%) were reported as the most important reason for domestic violence in previous studies[8]. Arguments, poor socio-economic status, poor educational status and love affairs have been reported as reasons for domestic violence in Sri Lanka [9, 10]. Arguments were reported the reason for violence among husband and wife in our study.

The physical injuries following domestic violence vary from mild to severe in severity in the form of contusions, laceration, cut injury, burn injury, fractures and head injury $[11,12]$. Most people have sustained minor injuries such as contusion (64.4\%), laceration (15.3\%) in our study.

The prevalence of domestic injuries is high in South Asian countries especially among females in the community [9]. It also been observed that the prevalence of domestic violence has increased in Northern and Eastern provinces of Sri Lanka following the end of war in 2009 [14]. Several studies reported that most of the people seeking healthcare services do not disclose domestic violence [9]. Most housewives usually do not want to report their harassments due to several reasons, particularly concern about their children, lack of social and economic support and dependence on husband [3]. Lack of education and economic dependence also make them less confident to disclose their problems to medical professionals. The majority of females who have been exposed to domestic violence do not seek medical attention and have continued to live with their abusers for long years in Sri Lanka [13]. Our study showed that $47.5 \%$ of the victims lived with their abusers and avoided seeking medico-legal action various reasons such as fear of family separation, isolation from community and future of children. Most of the women believed that they have to be obedient to their husbands and that the husband is the sole authority of the matrimonial household.
In summary, recently, there is a positive attitude towards prevention of domestic violence in Sri Lanka. However, it is necessary to encourage females to seek medical attention and outside services if they are exposed to domestic violence [11]. There are still several barriers which discourage women from seeking attention following domestic violence. These barriers should be addressed by society, medical professionals and women themselves. Most of the victims have reported that good knowledge, leadership skills and adequate family income would encourage them to overcome sufferings from domestic violence which is also reported in our study. The empowerment and leadership ability of women especially in the form of economic productivity, higher education and breaking up poor cultural background will help to reduce the prevalence of domestic violence near future in Sri Lanka [11].

\section{Conclusion}

Domestic violence is common among young females and was associated with illiteracy, the poor socioeconomic status of the victims. Arguments and financial problems are the commonest reason for violence. Most of the people are not aware of seeking medico-legal action due to fear of separation and future of children. Husbands are the main perpetrators of violence against their wives. We emphasize the urgent requirement of multidisciplinary interventional approach to improve public health measures, which would most effectively address this issue, and create awareness and bring new alteration in attitudes among society.

All authors disclose no conflict of interest. The study was conducted in accordance with the ethical standards of the relevant institutional or national ethics committee and the Helsinki Declaration of 1975, as revised in 2000 .

\section{References}

1. Kalokhe AS, Potdar RR, Stephenson R, et al. How well does the World Health Organization definition of domestic violence work for India?. PLoS One. 2015; 10 (3): https://doi:10.1371/journal.pone.0120909

2. World Health Organization. Global and regional estimates of violence against women: prevalence and health effects of intimate partner violence and non-partner sexual violence.

Geneva, Switzerland 2013. Available at;

https://www.who.int/reproductivehealth/publications/violence/9 789241564625/en/.

3. Jayasuriya V, Wijewardena K, Axemo P. Intimate Partner Violence of women in the Capital province of Sri Lanka: prevalence, risk factors and help seeking. Violence Against Women 2011; 17: 1086-102. https://doi.org/10.1177/1077801211417151.

4. Kocacik F, Dogan O. Domestic violence against women in Sivas, Turkey: Survey study. Croat Med J. 2006;47:742-9.

https://www.ncbi.nlm.nih.gov/pubmed/17042066. 
5. Bates LM, Schuler SR, Islam F, Islam MK. Socio-economic factors and processes associated with domestic violence in rural Bangladesh. Int Fam Plan Perspect. 2004;30:190-9. https://doi.org/10.1363/ifpp.30.139.04.

6. Gomez S. A study on gender based violence in the Batticaloa district. Care International-Sri Lanka 2005; 1: 1-92.

Available at;

http://actnowsrilanka.org/en/reports/122-a-study-on-genderbased-violence-in-the-batticaloa-district.

7. Subramanium P, Sivayogan S. The prevalence and pattern of wife beating in the Trincomalee District in eastern Sri Lanka. Southeast Asian J Trop Med Public Health.2001; 32:186-195. Available at; https://www.ncbi.nlm.nih.gov/pubmed/11485084.

8. Nair U, Sadhwani H, Uttekar V. CRDC Research Summary. Baroda: Centre for Research in Development and Change; 2000. A study on domestic violence in rural Gujarat. Available at; http://shodhganga.inflibnet.ac.in/bitstream/10603/116992/9/09 chapter\%203.pdf.

9. Vidanapathirana M. Factors related to wife-battering; a medicolegal analysis. Galle Med J 2014; 19: 6-10.

http://dx.doi.org/10.4038/gmj.v19i1.6958.
10.Deraniyagala S. An investigation into the incidence and causes of domestic violence in Colombo, Sri Lanka. WIN 1992.Available at;

http://www.actnowsrilanka.org/en/books/36-violence-againstwomen-in-asia.

11.S Guruge, V Jayasuriya-Illesinghe, N Gunawardena, J Perera. Intimate partner violence in Sri Lanka: a scoping review. Ceyl Med J 2015; 60:133-138. https://doi.org/10.4038/cmj.v60i4.8100.

12.Saravanapavanthan S. Wife beating: a study of sixty cases. Forensic Sci Int 1982; 29: 163-6.

13.Jayatilleke A, Poudel KC, Sakisaka K, Yasuoka J, Jayatilleke AU, Jimba M.Wives' attitudestoward gender roles and their experience of intimate partner violence by husbands in CentralProvince, Sri Lanka. J Interpers Violence. $2011 ; 26$ (3):414-32. https://doi.org/10.1177/0886260510363420.

14.Guruge S, Ford-Gilboe M, Varcoe C, Jayasuriya-Illesinghe V, Ganesan M, Sivayogan S et al.,Intimate partner violence in the postwar context: Women's experiences and community leaders' perceptions in the Eastern Province of Sri Lanka. PLoS ONE ;2017;12(3).

https://dx.doi.org/10.1371\%2Fjournal.pone.0174801. 